\section{Is There Variability for Xylem Vulnerability to Cavitation in Walnut Tree Cultivars and Species (Juglans spp.)?}

\author{
Wanploy Jinagool and Lia Lamacque \\ UCA, INRA, PIAF, 63000 Clermont-Ferrand, France
}

Marine Delmas

INRA, UEA, CRB Juglans, 33210 Toulenne, France

\author{
Sylvain Delzon \\ BIOGECO, INRA, University of Bordeaux, Cestas 33610, France
}

\author{
Hervé Cochard and Stéphane Herbette ${ }^{1}$ \\ UCA, INRA, PIAF, 63000 Clermont-Ferrand, France
}

Additional index words. Cavitron, drought, hydraulics

\begin{abstract}
Drought-tolerance selection is a current challenge for breeding programs to ensure agrosystem resilience, particularly with intensity and frequency of drought increasing worldwide. In tree species, xylem vulnerability to cavitation is among the most important traits on which drought-induced mortality depends. It can be rapidly evaluated, enabling large-scale screening for drought resistance. Genetic variability and phenotypic plasticity for this trait have been studied in natural populations, but not yet for cultivated tree species. In this work, the genetic variability in xylem vulnerability to cavitation of six Persian walnuts (Juglans regia L.), six hybrid walnuts (J. regia $\times$ Juglans nigra), and seven walnut species was investigated. In the first step, the method for measuring xylem vulnerability to cavitation using the "Cavitron" centrifuge technique was improved on walnut samples to obtain more accurate results. The Cavitron technique was found well suited to assessing xylem vulnerability to cavitation on this species using a $0.38 \mathrm{~m}$ rotor, which is large enough to analyze samples with intact vessels. Despite differences in wood anatomical traits, xylem vulnerability to cavitation among the Persian walnuts studied was similar. Very narrow variations in xylem vulnerability to cavitation were also found among hybrid walnuts. Only slight differences were observed on comparing species among which some have shown differences in various traits. These results suggest uniform selection, leading to canalization in cavitation resistance for cultivated Juglans.
\end{abstract}

Water resource management in agriculture, the largest user of this resource, is of growing importance, especially as it is predicted that droughts will be more frequent and severer. In this context, selection for drought-tolerant crops, particularly perennials, is a major challenge to ensure crop productivity. According to the cohesiontension theory, sap flows from root to shoot in vascular plants through xylem conduits under negative pressure (Dixon and Joly, 1894). This negative pressure makes the liquid sap metastable, with a risk of vaporization by cavitation inside conduits, which increase considerably in plants during drought. Cavitation causes a conduit to become air-filled or embolized and unable to

Received for publication 1 Aug. 2017. Accepted for publication 10 Dec. 2017.

We thank Pierre Conchon (PIAF laboratory) for his technical support in hydraulics and wood anatomy. ${ }^{1}$ Corresponding author. E-mail: stephane.herbette@ uca.fr. found within populations (Hajek et al., 2016; Lamy et al., 2011; Wortemann et al., 2011) with few differences between populations, indicating that this trait is genetically canalized in natural populations (Lamy et al., $2011,2014)$. The genetic variability for vulnerability to cavitation needs also to be tested on cultivated fruit trees. Such fruit trees have been subjected to different selection pressures from natural populations, and they are not subject to natural selection pressures that could reduce the variability. In addition, the effect of the selection on vulnerability to cavitation is unclear as there are contrasting data on the relationship between yield traits and vulnerability to cavitation (Cochard et al., 2007; Guet et al., 2015; Lamy et al., 2011).

Walnut species (Juglans spp.) are economically important. The most important are the Persian walnut (J. regia L.) and the eastern black walnut ( $J$. nigra L.), which are cultivated for nut and wood production in the United States, Europe, and Asia. The important cultivation areas are located in Mediterranean, semiarid, and arid regions (Aletá et al., 2009; Vahdati et al., 2009). They are considered as marginal production areas for this species because of low water availability. To date, few studies have been carried out to investigate genetic and phenotypic variability in physiological responses of this genus to environmental factors, specifically to the responses of drought stress in the context of climate change (Crystal and Jacobs, 2014; Gauthier and Jacobs, 2011).

Walnut is a drought-avoidant species (Lucier and Hinckley, 1982). It displays several desiccation-avoidance mechanisms, such as deep root system (Pallardy and Rhoads, 1993), stomatal sensitivity to relative humidity (Cochard et al., 2002), and drought-induced leaf abscission (Tyree et al., 1993). These traits help prevent extensive cavitation developing during water stress. Previous studies have pointed out the differences in water use efficiency or drought response for germination and growth between Persian walnut genotypes. These studies suggested a difference in drought responses among the genotypes (Aletá et al., 2009; Vahdati et al., 2009). However, little is known about genetic variability for drought tolerance traits, particularly for vulnerability to cavitation.

In this study, we assessed the genetic diversity of vulnerability to cavitation in Juglans spp. First, we tested several methods for measuring vulnerability to cavitation for improving the accuracy of vulnerability curves (VCs) in this tree species. We then investigated this trait in six cultivars of $J$. regia, six hybrids of $J$. regia $\times J$. nigra, and seven species in relation with xylem structural traits. We hypothesized that the variation in vulnerability to cavitation would be much higher in the species and the hybrids than in the commercial cultivars, as the genetic variability is higher among species, and could be enhanced by interspecific crossing (Cochard et al., 2008). 


\section{Materials and Methods}

Plant materials. The measurements were conducted on walnut trees $18-23$ years old, grown outdoors at the INRA (Institut National de Recherche Agronomique) Crouël site, Clermont-Ferrand in south-central France (lat. $45^{\circ} 46^{\prime} 27^{\prime \prime} \mathrm{N}$, long. $3^{\circ} 8^{\prime} 36^{\prime \prime} \mathrm{E}$; altitude $338 \mathrm{~m})$. Forty-eight individual trees were selected from six cultivars: Chandler (Ch, 4 individuals), Fernette (Ft, 3), Fernor (Fo, 4), Franquette (Fq, 17), Lara (La, 15), and Serr $(\mathrm{Se}, 4)$. The selected trees were in the same area, had the same south orientation, and had similar height aboveground level. The trees were neither irrigated, nor fertilized, nor treated. Seventeen branch samples were randomly harvested from the 48 trees to test the analytical technique using Cavitron on 4 Oct. 2011. Three to six branches were later collected from each tree studied to investigate the level of vulnerability to cavitation among these cultivars on 8 Nov. 2011. Selected branches were current year, mature, from the sun-exposed part of the canopy, and at least $0.45 \mathrm{~m}$ in length. Branches were immediately defoliated, wrapped in moist paper, and placed in plastic bags to avoid dehydration. The branches were cold-stored $\left(4^{\circ} \mathrm{C}\right)$ for not more than $30 \mathrm{~d}$ before analysis of their xylem vulnerability to cavitation. We previously demonstrated that autumn sampling was well suited to measuring this trait and that samples could be stored for several weeks before measurements (Herbette et al., 2010).

In addition, 20 branches were randomly harvested from these trees following the same protocols, for the measurement of native embolism. These harvested branches were placed in moist black plastic bags and brought immediately to the laboratory for analysis. Comparison for vulnerability to cavitation between walnut hybrids was conducted on six wood-oriented hybrid walnuts $($ J. regia $\times J$. nigra $): \mathrm{F} 1, \mathrm{~F} 2, \mathrm{H} 3, \mathrm{~J} 3, \mathrm{~N} 1$, and $\mathrm{N} 3$, grown on the same site. Branches 0.60 $1.00 \mathrm{~m}$ long were collected on 12 Nov. 2013. For each hybrid, current year branches $(n=8-10)$ were collected from sunlight-exposed parts of two individual trees. The sampling was carried out as described previously.

Comparison for vulnerability to cavitation among walnut species was conducted on trees 28-30 years old grown outdoors at the INRA Toulenne site in southwestern France (lat. $44^{\circ} 43^{\prime} 36^{\prime \prime} \mathrm{N}$, long. $0^{\circ} 16^{\prime} 43^{\prime \prime} \mathrm{E}$ ). Fiftynine branches $0.60-1.00 \mathrm{~m}$ long were collected from seven walnut species: Juglans cinerea, Juglans hindsii, Juglans mandshurica, J. nigra, J. regia, Juglans microcarpa, and Juglans ailantifolia. For each species, current year branches $(n=4-16)$ were collected from sunlight-exposed parts of three to seven individual trees. The sampling was carried out as described previously.

Native embolism. Native embolism was measured on branches of both Persian $(n=15)$, the hybrid $(n=12)$ and the species $(n=26)$ of walnut, using Xyl'EM and following the procedure described by Cruiziat et al. (2002). This prerequisite was proposed and explained by Awad et al. (2010). Briefly, a high level of native embolism can underestimate the vulnerability to cavitation measured using the Cavitron. It is, thus, necessary to control the native embolism of samples before analyzing vulnerability to cavitation. A segment $0.1 \mathrm{~m}$ long was cut under water from the center of the collected branch, and its proximal end was then attached to the hydraulic apparatus. Initial hydraulic conductance $\left(K_{\mathrm{i}}\right)$ was measured under low pressure $(6-9 \mathrm{kPa})$ using a perfused solution of $10 \mathrm{~mm} \mathrm{KCl}$ and $1 \mathrm{~mm}$ $\mathrm{CaCl}_{2}$. The segments were perfused with the same solution at $0.15 \mathrm{MPa}$ to remove embolism, and the maximum hydraulic conductance $\left(K_{\max }\right)$ was determined under low pressure. The percent loss of xylem conductivity (PLC) was calculated as follows:

$$
P L C=100 \times\left(1-K_{\mathrm{i}} / K_{\max }\right) .
$$

Estimation of the maximal vessel length. Cut-open vessels on samples are more sensitive to cavitation than intact ones. They yield abnormal r-shape VC when measuring xylem vulnerability to cavitation using the Cavitron (Cochard et al., 2010). Before the branch segments underwent measurement of xylem vulnerability to cavitation in this technique, they were checked for the presence of open vessels using the air infiltration technique (Ewers and Fisher, 1989; Zimmermann and Jeje, 1981). After branches were cut in the air to obtain the desired length $(0.28$ and $0.38 \mathrm{~m}$ long), they were successively infiltrated with compressed air $(0.10 \mathrm{MPa})$ at one end, whereas the other end was submerged in water. Air bubbles were observed when vessels were cut open.

Xylem vulnerability to cavitation. Xylem vulnerability to cavitation was measured by the Cavitron method (Cochard, 2002; Cochard et al., 2005). The principle of this technique is to use centrifugal force to increase the tension in the water columns while measuring the decrease in hydraulic conductance. The branches were prepared by peeling off bark at both the ends and cutting in the air to obtain a fixed length. We first used branches 0.28 and $0.38 \mathrm{~m}$ long from Persian walnuts to test the effect of the sample length on the measurements. These lengths are imposed by the diameters of the rotors used. The following measurements were then all performed on segments $0.38 \mathrm{~m}$ long. We also tested the effect of the water flow direction on the measurements (sense and antisense flows). In the spinning Cavitron, water ran from an upstream reservoir to the downstream part (Cochard, 2002). The flow direction was controlled by the relative position of the reservoirs at the sample ends. The flow from the proximal to the distal end of the sample is the sense flow and the flow from the distal to the proximal end is the antisense flow. Xylem pressure $(P)$ was first set to a reference pressure $(-0.75 \mathrm{MPa})$ and $K_{\max }$ was determined. The xylem pressure was then set to more negative pressure and the new sample conductance $\left(K_{\mathrm{i}}\right)$ was determined.
The procedure was repeated for more negative pressures (with -0.25 or $-0.50 \mathrm{MPa}$ increments) until the PLC reached at least $90 \%$. The PLC of the stem was computed according to Eq. [1]. After measurement, the samples were stored at $-30{ }^{\circ} \mathrm{C}$ for further analysis on wood anatomy. The $\mathrm{VC}$ was later constructed by plotting PLC vs. xylem water tension. For each curve, the raw data were fitted using the sigmoid function (Pammenter and Van der Willigen, 1998):

$$
P L C=100 /\left(1+e^{\left(s /\left(25\left(P-P_{50}\right)\right)\right)}\right)
$$

where $P_{50}(\mathrm{MPa})$ is the pressure causing $50 \%$ loss of xylem conductivity and $s$ is the slope of VC. The xylem water potential causing $12 \%$ and $88 \%$ loss of xylem conductivity $\left(P_{12}\right.$ and $P_{88}$, respectively) were calculated from Eqs. [3] and [4]:

$$
P_{12}=P_{50}+50 / s
$$

$$
P_{88}=P_{50}-50 / s
$$

where $P_{12}$ is considered as the "air entry point" where the embolism begins (Sparks and Black, 1999) and $P_{88}$ is the "full embolism point"; the tension before the xylem becomes totally nonconductive (Domec and Gartner, 2001).

Wood anatomical traits. Wood infradensity (WD, $\mathrm{g} \cdot \mathrm{cm}^{-3}$ ) was measured in two segments from the proximal part of each sample used for xylem vulnerability analysis. WD was determined by the following equation:

$$
\mathrm{WD}=M_{0} / V_{\mathrm{s}}
$$

where $V_{\mathrm{s}}$ is the fresh volume $\left(\mathrm{cm}^{3}\right)$ and $M_{0}$ is the dry mass $(\mathrm{g})$.

Fresh volumes of segments 3-cm long were measured by water displacement on an analytical balance. To measure the fresh volume as accurately as possible, the sample segments were previously fully hydrated by placing them in deionized water under vacuum. Samples were then dried in a kiln at $70{ }^{\circ} \mathrm{C}$ for two days, and their dry weights were measured.

For wood anatomy analyses, cross sections of the midpart of the samples were prepared and dyed with Safranin. They were examined under an optical microscope $(\times 20)$, and images were recorded using a digital camera (AxioCam HR, Zeiss, Jéna, Germany). The wood anatomy was determined by image analysis using ImageJ software (Rabsand, 1997-2009). The vessels were isolated by automatic segmentation, and their diameters $(\mu \mathrm{m})$, density (number $\left./ \mathrm{mm}^{2}\right)$, and lumen vessel areas $\left(A_{\mathrm{v}}, \%\right)$ were then measured.

Statistics. Analysis of variance (ANOVA) was applied to test the effects of the following parameters on vulnerability to cavitation: length of branch segments, direction of water flows, and walnut cultivars, hybrids, and species. When significant differences were found, Duncan's multiple range test with $P<$ 0.05 was applied. These statistical analyses, together with the calculation of the coefficient of determination $\left(R^{2}\right)$, were carried out using XLSTAT software. 


\section{Results}

Methodological analysis on the measurement of vulnerability to cavitation. The VCs with segments 0.28 and $0.38 \mathrm{~m}$ long displayed slight differences in shape, and their mean $P_{50}$ values were significantly different $(P<0.05)$ with values of $-1.65 \mathrm{MPa}(\mathrm{SE} \pm 0.03)$ and -1.99 $\mathrm{MPa}(\mathrm{SE} \pm 0.04)$, respectively (Fig. 1A). Air bubbles were observed on some branch segments $0.28 \mathrm{~m}$ long, but none was observed on those $0.38 \mathrm{~m}$ long, on infiltrating them with air. These results indicated that the maximum vessel length of the walnut cultivars studied lay between 0.28 and $0.38 \mathrm{~m}$. The tested water flow directions through the spinning sample on the Cavitron (Fig. 1B) gave sigmoidal VCs for both sense and antisense flows and showed no significant difference in $P_{50}(-1.99$ and $-2.02 \mathrm{MPa}$, respectively). However, the data set on the antisense flow fitted the logistic line better than the data set on the sense flow. The coefficients of determination $\left(R^{2}\right)$ for sense and antisense flows were 0.979 and 0.994 , respectively. We, thus, continued the analyses with samples $0.38 \mathrm{~m}$ long and antisense flow.
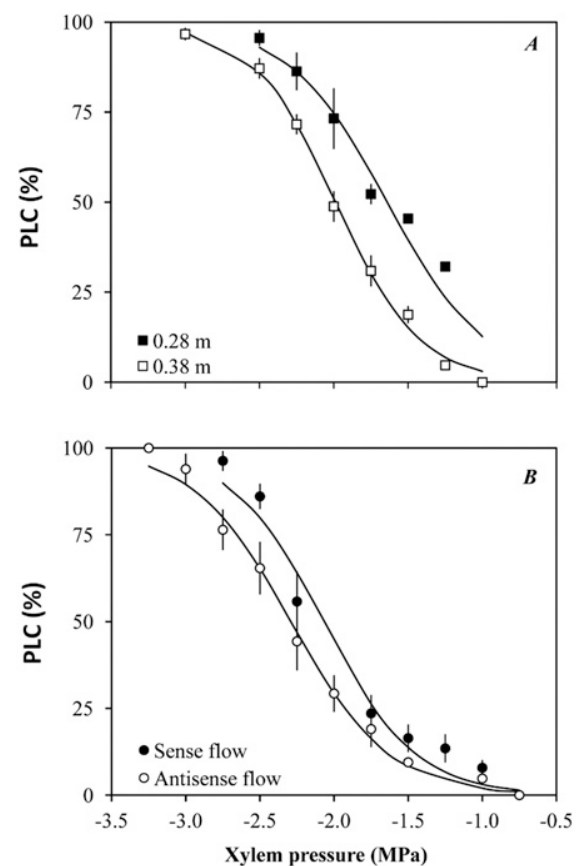

Fig. 1. Effect of the sample size (A) and the water flow direction (B) on the xylem vulnerability to cavitation of walnut branches. Vulnerability curves (VCs) show the mean percentage loss of xylem conductivity (PLC, \%) plotted vs. the xylem water potential. Lines are logistic fitted to the data and error bars are SE $(n=3-6)$. (A) Xylem vulnerability to cavitation was measured on segments $28-\mathrm{cm}$ long (-) and on segments 38-cm long ( $\square$ ). (B) Xylem VCs obtained when water flows from the proximal to the distal part of the sample (-, sense flow) or from the distal to the proximal part of the sample $(\bigcirc$, antisense flow). Normal sigmoidal curves were obtained from both senses of water flow; however, the antisense flow gave data that fitted better to the logistic line $\left(R^{2}=0.979\right.$ and 0.994 for sense and antisense flows, respectively).
Xylem vulnerability to cavitation on Persian, hybrids and species walnuts. The native embolism measured on Persian walnuts ranged from $22.71 \%$ to $38.41 \%$ $(\bar{x}=30.70 \% \pm 5.82 \%)$, whereas on the hybrids, it ranged from $13.80 \%$ to $27.14 \%(\bar{x}=$ $19.09 \% \pm 7.08 \%$ ). Between species, it ranged from 12.40 to 25.01 ( $\bar{x}=16.22 \% \pm 8.0 \%$ ); it showed no significant differences between mean values in native embolism $(P<0.05)$. This test was a prerequisite to avoid the effect of the native embolism on the vulnerability to cavitation measured with Cavitron.

The VCs are shown in Fig. 2A for six Persian walnut cultivars, Fig. 2B for six hybrid walnuts, and Fig. $2 \mathrm{C}$ for seven walnut species. Vulnerability to cavitation parameters $\left(P_{12}, P_{50}, P_{88}\right.$, and $\left.s\right)$ obtained for the cultivars, hybrids, and species are presented in Table 1. Both the VCs and $P_{50}$ values were not significantly different among the Persian walnut cultivars, mean $P_{50}$ ranging from -1.93 to $-1.98 \mathrm{MPa}$. According to the ANOVA analysis, most of the variability was observed within the cultivar $(97.52 \%)$, whereas only $2.48 \%$ was the effect of the cultivars. Weak but significant differences were found for $P_{12}$ and $P_{88}$ between the cultivars. No significant differences were found for the xylem vulnerability to cavitation parameters $(P>0.05)$ among the hybrid walnuts and among the species. For hybrids, $P_{50}$ values ranged from -2.05 to $-2.23 \mathrm{MPa}$; the variation was mostly observed within the hybrids $(78.35 \%)$. For species, $P_{50}$ values ranged from -1.89 to $-2.16 \mathrm{MPa}$, and most of the variation was found within the species $(83.15 \%)$.

Wood anatomical traits. Means of WD for the six Persian walnut cultivars studied varied from 0.39 to $0.45 \mathrm{~g} \cdot \mathrm{cm}^{-3}$ with significant differences $(P<0.05)$ between $\mathrm{Se}$ and the following cultivars: Fo, Fq, Ft, and $\mathrm{La}$, whereas it was similar to $\mathrm{Ch}$ (Table 2). The statistical analysis indicated no significant difference $(P>0.05)$ between the six cultivars for the mean values of $D$ and vessel density (VD). However, a significant difference $(P<0.05)$ was found for $A_{\mathrm{v}}$ (Table 2$)$ between the cultivars $\mathrm{Ch}$ and Se showing the highest $A_{\mathrm{v}}$ and the cultivar Ft showing the lowest $A_{\mathrm{v}}$. Significant differences $(P<0.05)$ were observed between some species for VD and $A_{\mathrm{v}}$ but not for $D$.

\section{Discussion}

The investigation of genetic variability in xylem vulnerability to cavitation is of interest in breeding for drought tolerance. For the Persian walnut, the importance of exploring this trait is highlighted by the location of the primary production of the crop in droughtprone areas. Operational traits are needed to help breeders select for more suitable genotypes/cultivars that will survive in unfavorably dry conditions with reduced irrigation inputs in the future. Here, we first improved the measurement of this trait in walnut and went on to find that there were no differences between the commercial walnut cultivars examined or between the walnut species.
Methodological analysis on the measurement of vulnerability to cavitation. The "Cavitron" centrifugal technique (Cochard, 2002; Cochard et al., 2005) is an effective, rapid method for large-scale investigation of xylem vulnerability to cavitation (Cochard et al., 2016; Corcuera et al., 2011; Lamy et al., 2011; Wortemann et al., 2011) and could thus be used for competent screening of candidate genotypes for breeding. However, during the recent development of this technique, several methodological flaws have reportedly been introduced (Cochard et al., 2010; Delzon and Cochard, 2014; Torres-Ruiz et al., 2015, 2017; Wheeler et al., 2013). Although it is not the main aim of this study, we have addressed these methodological issues to ensure accurate measurement of the trait and reduce technical variability. The Cavitron technique can be applied only to samples with conduits shorter than the sample length. Conduits longer than the sample length generate a measurement artifact and an abnormal shape of the VC (Cochard et al., 2010; Martin-St Paul et al., 2014). From the results of methodological analyses, we recommend using segments $0.38 \mathrm{~m}$ long and working with the antisense flow direction to build the $\mathrm{VC}$ of the walnut tree. Both a longer segment and an antisense flow reduce the proportion of cutopen vessels, which are more sensitive to cavitation than the intact vessels and yield an abnormal VC. In the sensed flow, there are lateral flows due to the cut of leaves and branches along the samples. These lateral flows depend more on the cut-open vessels, which are rapidly filled with air during the measurement. This would explain the greater variation in the measurement of vulnerability to cavitation, resulting in a poorer fit to logistic line data compared with data obtained with the antisense flow (Fig. 1).

Native embolism can lead to an underestimation of the xylem vulnerability to cavitation when only a few conduits are still functional during the measurements (usually the conduits most resistant to cavitation). The rather low native embolism we measured here ensured that xylems of the samples were not greatly embolized by previous drought or frozen stresses. This indicates that, avoiding any bias, xylem vulnerability to cavitation was measured on a large proportion of the functional conduits.

The $P_{50}$ values obtained in this study (mean $P_{50}=-1.97,-2.16$, and $-1.99 \mathrm{MPa}$ for Persian, hybrid, and species walnut, respectively) were in line with the previous results obtained from walnut trees (Cochard et al., 2002; Knipfer et al., 2015; Tyree et al., 1993) with different analytical techniques.

Comparison for vulnerability to cavitation between walnut tree accessions. Finding similar xylem vulnerability to cavitation for the six cultivars of Persian walnuts is rather surprising. Differences in the drought resistance traits were observed from previous studies between the cultivars; for example, differences in $\delta^{13} \mathrm{C}$ were found between 22 Persian walnuts from the different regions of 
provenance, indicating a variation in water use efficiency (Altá et al., 2009). The cultivars from the drought-prone provenance regions were found to be more efficient in water use. Difference in drought tolerance was also found between the cultivar we studied here,
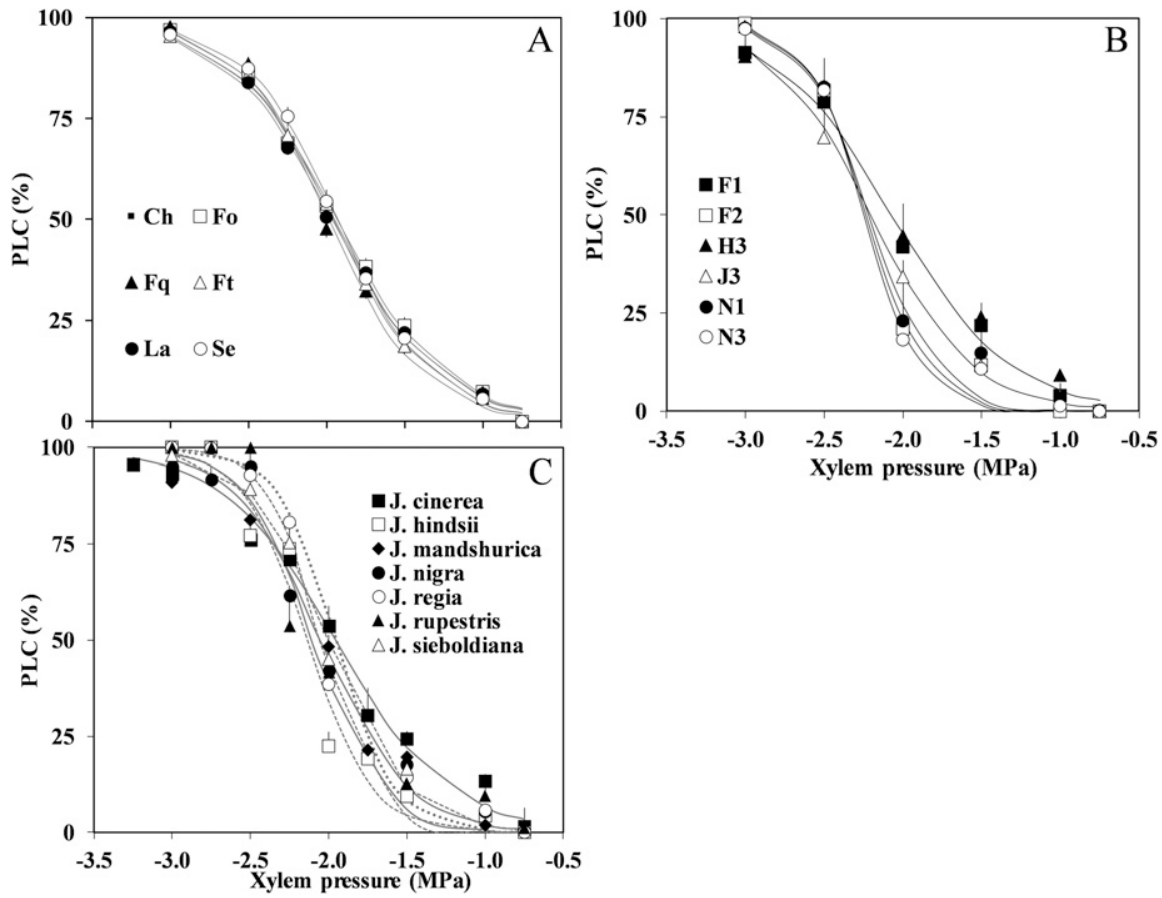

Fig. 2. Xylem vulnerability to cavitation of Persian walnut cultivars (A), hybrids (B), and species (C) Vulnerability curves (VCs) show the percentage loss of xylem conductivity (PLC, \%) plotted vs. the xylem water potential. Measurements were conducted on (A) six cultivars of Juglans regia: Chandler (Ch, $n=15)$, Fernette (Ft, $n=13)$, Fernor (Fo, $n=10)$, Franquette (Fq, $n=67)$, Lara (La, $n=42)$, and Serr (Se, $n=18$ ), (B) six hybrids of J. regia $\times$ Juglans nigra: F1, F2, H3, J3, N1, and N3 ( $n=4)$, and (C) seven Juglans species: Juglans cinerea $(n=12)$, Juglans Hindsii $(n=6)$, Juglans mandshurica $(n=4)$, J. nigra $(n=16)$, J. regia $(n=4)$, Juglans microcarpa $(n=5)$, and Juglans ailantifolia $(n=12)$. Dots are mean values with fitted logistic lines and bars are SE. the values were remarkably close. These results may contribute to the similar vulnerability to cavitation found among the Persian walnuts and the hybrids found in this study, previous studies having demonstrated a correlation between vulnerability to cavitation and wood anatomy traits (Guet et al., 2015; Hacke et al., 2001; Lens et al., 2011).

Given the lack of difference between these Persian walnut cultivars, we investigated the vulnerability to cavitation of $J$. regia $\times J$. nigra hybrids to enhance the range of genetic diversity, and then between the different Juglans species. We expected to find a genetic variability at the higher taxonomic ranks. High vulnerability to cavitation was found when comparing Prunus species (Cochard et al., 2008). A review of the hydraulic traits in conifers also reveals differences between species from the same genus, although it is weaker in some genera such as Pinus (Bouche et al., 2014; Larter et al., 2017; Martínez-Vilalta et al., 2004). However, we found a similar vulnerability to cavitation among the hybrid walnuts studied, as well as between the seven species studied among the whole thirteen. This study is the first comparison of vulnerability to cavitation for several walnut species, showing that there is no difference between species in the Juglans genus. Yet, the seven species in our experimental orchard represent a large part of the Juglans diversity, encompassing the four Juglans sections (Stanford et al., 2000): Cardiocaryon ( $J$. mandshurica, $J$. ailantifolia), Dioscaryon (J. regia), Rhysocaryon ( $J$. nigra, J. microcarpa, J. hindsii), and Trachycaryon (J. cinerea). These similar cavitation resistances, despite the large variations reported for other traits, suggest a "uniform selection" on this trait within Juglans. Such uniform selection for this trait has been

Table 1. Parameters of xylem vulnerability to cavitation in walnut cultivars, hybrids, and species.

\begin{tabular}{|c|c|c|c|c|c|}
\hline Level of comparison & Cultivars/hybrids/species & $P_{12}(\mathrm{MPa})$ & $P_{50}(\mathrm{MPa})$ & $P_{88}(\mathrm{MPa})$ & $s(\% / \mathrm{MPa})$ \\
\hline \multirow{4}{*}{ Juglans regia } & Franquette & $-1.40(0.02) \mathrm{b}$ & $-1.98(0.01)$ & $-2.56(0.02) \mathrm{a}$ & $89.46(2.20)$ \\
\hline & Fernette & $-1.33(0.04) \mathrm{ab}$ & $-1.96(0.02)$ & $-2.58(0.03) \mathrm{ab}$ & $81.68(3.81)$ \\
\hline & Serr & $-1.34(0.03) a b$ & $-1.93(0.02)$ & $-2.52(0.04) \mathrm{a}$ & $88.84(4.65)$ \\
\hline & Mean & $-1.34(0.01)$ & $-1.97(0.01)$ & $-2.59(0.01)$ & $83.41(1.37)$ \\
\hline \multirow[t]{4}{*}{ J. regia $\times$ Juglans nigra } & F1 & $-1.34(0.07)$ & $-2.07(0.04)$ & $-2.80(0.03)$ & $68.77(3.51)$ \\
\hline & N1 & $-1.81(0.27)$ & $-2.20(0.13)$ & $-2.59(0.02)$ & $230.24(114.54)$ \\
\hline & N3 & $-1.84(0.16)$ & $-2.23(0.08)$ & $-2.62(0.06)$ & $149.31(2.95)$ \\
\hline & Mean & $-1.63(0.07)$ & $-2.16(0.03)$ & $-2.70(0.04)$ & $127.03(21.81)$ \\
\hline \multirow[t]{3}{*}{ Juglans sp. } & Juglans cinerea & $-1.36(0.07)$ & $-1.89(0.07)$ & $-2.43(0.12)$ & $121.59(19.85)$ \\
\hline & Juglans hindsii & $-1.78(0.11)$ & $-2.16(0.02)$ & $-2.54(0.09)$ & $398.81(263.78)$ \\
\hline & Juglans Mandshurica & $-1.58(0.24)$ & $-1.99(0.02)$ & $-2.40(0.21)$ & $177.36(98.30)$ \\
\hline
\end{tabular}

Xylem pressure causing $12 \%, 50 \%$, and $88 \%$ loss of xylem hydraulic conductivity $\left(P_{12}, P_{50}\right.$, and $\left.P_{88}\right)$ and the slope of the VC(s) were calculated from the curves of vulnerability to cavitation in six cultivars of $J$. regia, in six hybrids of $J$. regia $\times$ J. nigra and in seven Juglans species. Values represent means with sE in the brackets, $n=4$ for each hybrid while $n \geq 10$ for each $J$. regia cultivars and $n \geq 4$ for each walnut species. Means were compared between $J$. regia cultivars, between hybrids, and between species. Values with different letters are significantly different at $P<0.05$ (Duncan's multiple range test). Bold values were means for cultivars, hybrids and species, respectively. 
Table 2. Wood anatomical traits of the six Persian walnuts cultivars and seven walnuts species.

\begin{tabular}{|c|c|c|c|c|c|}
\hline Level of comparison & Cultivars/species & $\mathrm{WD}\left(\mathrm{g} \cdot \mathrm{cm}^{-3}\right)$ & $D(\mu \mathrm{m})$ & VD (number $/ \mathrm{mm}^{2}$ ) & $A_{\mathrm{v}}$ \\
\hline \multirow[t]{4}{*}{ Juglans regia } & Chandler (Ch) & $0.42(0.01) \mathrm{ab}$ & $75.46(4.48)$ & $42.56(5.69)$ & $0.27(0.02) \mathrm{a}$ \\
\hline & Franquette (Fq) & $0.45(0.01) \mathrm{a}$ & $76.80(2.31)$ & $35.32(4.40)$ & $0.20(0.01) a b$ \\
\hline & Fernette $(\mathrm{Ft})$ & $0.43(0.01) \mathrm{a}$ & 75.07 (3.09) & $41.32(2.91)$ & $0.17(0.01) b$ \\
\hline & Serr (Se) & $0.39(0.01) \mathrm{b}$ & $80.68(4.39)$ & $46.26(3.50)$ & $0.27(0.03) \mathrm{a}$ \\
\hline \multirow[t]{5}{*}{ Juglans sp. } & Juglans cinerea & ND & $62.03(1.00)$ & $46.09(3.31) \mathrm{ab}$ & $0.087(0.006) \mathrm{ab}$ \\
\hline & Juglans hindsii & ND & $67.20(4.73)$ & $67.91(4.25) \mathrm{bc}$ & $0.149(0.007) \mathrm{c}$ \\
\hline & Juglans regia & ND & $66.17(5.09)$ & $35.74(2.26) \mathrm{a}$ & $0.079(0.008) \mathrm{a}$ \\
\hline & Juglans microcarpa & ND & $60.95(2.41)$ & $65.07(8.73) \mathrm{c}$ & $0.123(0.024) b c$ \\
\hline & Juglans ailantifolia & ND & $66.20(4.24)$ & $51.69(4.49) \mathrm{bc}$ & $0.124(0.031) b c$ \\
\hline
\end{tabular}

Wood density (WD) was measured on $\mathrm{Ch}(n=15), \mathrm{Ft}(n=13), \mathrm{Fo}(n=10), \mathrm{Fq}(n=68), \mathrm{La}(n=42)$, and $\mathrm{Se}(n=18)$ while vessel diameter $(D)$, vessel density (VD), and vessel lumen area $\left(A_{\mathrm{v}}\right)$ were analyzed on five branches for each cultivar and four or five branches for each species. Values represent means with SE in the brackets. Means were compared between $J$. regia cultivars and between species. Values with different letters are significantly different at $P<0.05$ (Duncan's multiple range test), whereas no letter means that no significant difference was observed. $\mathrm{ND}=$ not determined.

demonstrated in natural populations of Pinus pinaster (Lamy et al., 2011, 2014). To validate this finding for the walnut trees, further molecular analyses will be needed to quantify the neutral genetic diversity. In summary, these results suggest that vulnerability to cavitation does not vary in a branch of walnut and that differences in the drought resistance derive instead from drought-avoidance traits. Segmentation in xylem vulnerability to cavitation between the branch and petiole was reported in the walnut tree (Tyree et al., 1993), and a variation in the cavitation resistance of petiole could, thus, be expected for petiole in the walnut cultivars. Supporting this, differences in vulnerability to cavitation in the petiole were observed between Hevea brasiliensis clones, whereas there was no difference between their stems (Jinagool et al., 2015); this can be interpreted as a difference in drought avoidance between clones.

What use can be made of vulnerability to cavitation in screening for drought resistance in walnut? The lack of variation in vulnerability to cavitation in the Persian walnut accessions hampers its use in breeding programs. Similarly, the unexpected low variation for this trait between the species, and to a lesser extent between the hybrids, decreases the chance of improving this trait using scion/ rootstock combination. Some Juglans species play an important role as rootstocks for commercial Persian walnut orchards (McGranahan and Leslie, 1991). Conversely, it would be possible to carry out a selection program for other traits of interest, including other drought-related traits, without unfavorable effects on the xylem vulnerability to cavitation. Differences between the cultivars and the hybrids are known for various traits, such as date of budbreak, chilling, and heat requirement, and growth rate (Charrier et al., 2011; Poirier et al., 2004). In addition, a rather low cavitation resistance for these commercial cultivars indicates a high potential for the breeding program to improve on this trait. The challenge will be finding the genotypes most resistant to cavitation, perhaps by examining the natural populations from extremely dry locations. A further challenge will be identifying the genetic components of this trait.

In drought, hydraulic failure is not only related to intrinsic xylem vulnerability to cavitation; a model highlighting the importance of the coordination between the stomata and the hydraulic traits indicates that they are not uniformly coordinated (MartinSt Paul et al., 2017). The other traits (including stomatal closure and residual water loss) have to be measured to discriminate among walnut genotypes for their resistance to hydraulic failure.

\section{Literature Cited}

Aletá, N., A. Vilanova, R. Díaz, and J. Voltas. 2009. Genetic variation for carbon isotope composition in Juglans regia L.: Relationships with growth, phenology and climate of origin. Ann. For. Sci. 66:413.

Awad, H., T. Barigah, E. Badel, H. Cochard, and S. Herbette. 2010. Poplar vulnerability to xylem cavitation acclimates to drier soil conditions. Physiol. Plant. 139:280-288.

Bouche, P.S., M. Larter, J.C. Domec, R. Burlett, P. Gasson, S. Jansen, and S. Delzon. 2014. A broad survey of hydraulic and mechanical safety in the xylem of conifers. J. Expt. Bot. 65:4419-4431.

Charrier, G., M. Bonhomme, A. Lacointe, and T. Ameglio. 2011. Are budburst dates, dormancy and cold acclimation in walnut trees (Juglans regia $\mathrm{L}$.) under mainly genotypic or environmental control? Intl. J. Biometeorol. 55:763-774.

Choat, B., S. Jansen, T.J. Brodribb, H. Cochard, S. Delzon, R. Bhaskar, S.J. Bucci, T.S. Feild, S.M. Gleason, U.G. Hacke, A.L. Jacobsen, F. Lens, H. Maherali, J. Martinez-Vilalta, S. Mayr, M. Mencuccini, P.J. Mitchell, A. Nardini, J. Pittermann, R.B. Pratt, J.S. Sperry, M. Westoby, I.J. Wright, and A.E. Zanne. 2012. Global convergence in the vulnerability of forests to drought. Nature 491:752-755.

Cochard, H. 2002. A technique for measuring xylem hydraulic conductance under high negative pressures. Plant Cell Environ. 25:815819.

Cochard, H. 2006. Cavitation in trees. C. R. Phys. 7:1018-1126.

Cochard, H., S.T. Barigah, M. Kleinhentz, and A. Eshel. 2008. Is xylem cavitation resistance a relevant criterion for screening drought resistance among Prunus species? J. Plant Physiol. 165:976-982.
Cochard, H., E. Casella, and M. Mencuccini. 2007. Xylem vulnerability to cavitation varies among poplar and willow clones and correlates with yield. Tree Physiol. 27:1761-1767.

Cochard, H., L. Coll, X. Le Roux, and T. Ameglio. 2002. Unraveling the effects of plant hydraulics on stomatal closure during water stress in walnut. Plant Physiol. 128:282-290.

Cochard, H., G. Damour, C. Bodet, I. Tharwat, M. Poirier, and T. Ameglio. 2005. Evaluation of a new centrifuge technique for rapid generation of xylem vulnerability curves. Physiol. Plant. 124:410-418.

Cochard, H., S. Herbette, T. Barigah, E. Badel, M. Ennajeh, and A. Vilagrosa. 2010. Does sample length influence the shape of xylem embolism vulnerability curves? A test with the Cavitron spinning technique. Plant Cell Env. 33:15431552.

Cochard, H., J.M. Torres-Ruiz, and S. Delzon. 2016. Let plant hydraulics catch the waves. J. Plant Hydraul. 3:e02.

Corcuera, L., H. Cochard, E. Gil-Pelegrini, and E. Notivol. 2011. Phenotypic plasticity in mesic populations of Pinus pinaster improves resistance to xylem embolism $\left(P_{50}\right)$ under severe drought. Trees (Berl.) 25:1033-1042.

Cruiziat, P., H. Cochard, and T. Ameglio. 2002. Hydraulic architecture of trees: Main concepts and results. Ann. For. Sci. 59:723-752.

Crystal, P.A. and D.F. Jacobs. 2014. Drought and flood stress tolerance of butternut (Juglans cinerea) and naturally occurring hybrids: Implications for restoration. Can. J. For. Res. 44:1206-1216.

Delzon, S. and H. Cochard. 2014. Recent advances in tree hydraulics highlight the ecological significance of the hydraulic safety margin. New Phytol. 203:355-358.

Dixon, H.H. and J. Joly. 1894. On the ascent of sap. Proc. R. Soc. Lond. 57:3-5.

Domec, J-C. and B.L. Gartner. 2001. Cavitation and water storage capacity in bole xylem segments of mature and young Douglas-fir trees. Trees (Berl.) 15:204-214.

Ewers, F.W. and J.B. Fisher. 1989. Techniques for measuring vessel lengths and diameters in stems of woody plants. Amer. J. Bot. 76:645-656.

Gauthier, M-M. and D.F. Jacobs. 2011. Walnut (Juglans spp.) ecophysiology in response to environmental stresses and potential acclimation to climate change. Ann. For. Sci. 68:12771290.

Guet, J., R. Fichot, C. Ledee, F. Laurans, H. Cochard, S. Delzon, C. Bastien, and F. Brignolas. 2015. Stem xylem resistance to cavitation is related to 
xylem structure but not to growth and water-use efficiency at the within-population level in Populus nigra L. J. Expt. Bot. 66:4643-4652.

Hacke, U.G., J.S. Sperry, W.T. Pockman, S.D. Davis, and K.A. McCulloh. 2001. Trends in wood density and structure are linked to prevention of xylem implosion by negative pressure. Oecologia 126:457-461.

Hajek, P., D. Kurjak, G. von Wuhlisch, S. Delzon, and B. Schuldt. 2016. Intraspecific variation in wood anatomical, hydraulic, and foliar traits in ten European beech provenances differing in growth yield. Front. Plant Sci. 7:791.

Herbette, S., R. Wortemann, H. Awad, R. Huc, H. Cochard, and T.S. Barigah. 2010. Insights into xylem vulnerability to cavitation in Fagus sylvatica L.: Phenotypic and environmental sources of variability. Tree Physiol. 30:14481455.

Jinagool, W., R. Rattanawong, K. Sangsing, T.S. Barigah, F. Gay, H. Cochard, P. Kasemsap, and S. Herbette. 2015. Clonal variability for vulnerability to cavitation and other droughtrelated traits in Heva brasiliensis Müll. Arg. J. Plant Hydraul. 2:e001.

Knipfer, T., C.R. Brodersen, A. Zedan, D.A. Kluepfel, and A.J. McElrone. 2015. Patterns of drought-induced embolism formation and spread in living walnut saplings visualized using X-ray microtomography. Tree Physiol. 35:744-755.

Lamy, J.B., L. Bouffier, R. Burlett, C. Plomion, H. Cochard, and S. Delzon. 2011. Uniform selection as a primary force reducing population genetic differentiation of cavitation resistance across a species range. PLoS One 6:e23476.

Lamy, J.B., S. Delzon, P.S. Bouche, R. Alia, G.G. Vendramin, H. Cochard, and C. Plomion. 2014. Limited genetic variability and phenotypic plasticity detected for cavitation resistance in a Mediterranean pine. New Phytol. 201:874 886.

Larter, M., S. Pfautsch, J.C. Domec, S. Trueba, N. Nagalingum, and S. Delzon. 2017. Aridity drove the evolution of extreme embolism resistance and the radiation of conifer genus Callitris. New Phytol. 215:97-112.

Lens, F., J.S. Sperry, M.A. Christman, B. Choat, D. Rabaey, and S. Jansen. 2011. Testing hypotheses that link wood anatomy to cavitation resistance and hydraulic conductivity in the genus Acer. New Phytol. 190:709-723.

Lofti, N., K. Vahdati, B. Kholdebarin, and R. Amiri. 2010a. Drought-induced accumulation of sugars and proline in radicle and plumule of tolerant walnut varieties during germination phase. Acta Hort. 861:289-296.

Lofti, N., K. Vahdati, B. Kholdebarin, and R. Amiri. 2010b. Peroxidase, guaiacol peroxidase and ascorbate peroxidase activity accumulation in leaves and roots of walnut trees in response to drought stress. Acta Hort. 861:309-316.

Lofti, N., K. Vahdati, B. Kholdebarin, and R. Amiri. 2010c. Soluble sugars and proline accumulation play a role as effective indices for drought tolerance screening in Persian walnut (Juglans regia L.) during germination. Fruits 65:97-112.

Lucier, A. and T. Hinckley. 1982. Phenology, growth and water relations of irrigated and non-irrigated black walnut. For. Ecol. Mgt. 4:127-142.

Maherali, H., W.T. Pockman, and R.B. Jackson. 2004. Adaptive variation in the vulnerability of woody plants to xylem cavitation. Ecology 85:2184-2199.

Martin-StPaul, N., S. Delzon, and H. Cochard. 2017. Plant resistance to drought depends on timely stomatal closure. Ecol. Lett. 20:14371447.

Martin-StPaul, N.K., D. Longepierre, R. Huc, S. Delzon, R. Burlett, R. Joffre, S. Rambal, and H. Cochard. 2014. How reliable are methods to assess xylem vulnerability to cavitation? The issue of 'open vessel' artifact in oaks. Tree Physiol. 34:894-905.

Martínez-Vilalta, J., A. Sala, and J. Pinol. 2004. The hydraulic architecture of Pinanceae-A review. Oecologia 133:19-29.

McGranahan, G. and C. Leslie. 1991. Walnuts (Juglans). Acta Hort. 290:907-974.

Pallardy, S.G. and J.L. Rhoads. 1993. Morphological adaptations to drought in seedlings of deciduous angiosperms. Can. J. For. Res. 23:1766-1774.

Pammenter, N.W. and C. Vander Willigen. 1998. A mathematical and statistical analysis of the curves illustrating vulnerability of xylem to cavitation. Tree Physiol. 18:589-593.

Poirier, M., C. Bodet, S. Ploquin, B. Saint-Joanis, A. Lacointe, and T. Ameglio. 2004. Walnut cultivar performance of cold resistance in south central France. Acta Hort. 705:281-285.

Reid, W., M. Coggeshall, H.E. Garrett, and J. Van Sambeek. 2009. Growing black walnut for nut production, p. 1001. In: U.O. Missouri (ed.) The Center for Agroforestry, Columbia, MO.

Sancho-Knapik, D., J.J. Peguero-Pina, J. Flexas, S. Herbette, H. Cochard, U. Niinemets, and E. Gil-Pelegrin. 2014. Coping with low light under high atmospheric dryness: Shade acclima- tion in a Mediterranean conifer (Abies pinsapo Boiss.). Tree Physiol. 34:1321-1333.

Sparks, J.P. and R.A. Black. 1999. Regulation of water loss in populations of Populus trichocarpa: The role of stomatal control in preventing xylem cavitation. Tree Physiol. 19:453-459.

Stanford, A.M., R. Harden, and C.R. Parks. 2000. Phylogeny and biogeography of Juglans (Juglandaceae) based on matK and ITS sequence data. Amer. J. Bot. 87:872-882.

Torres-Ruiz, J.M., H. Cochard, B. Choat, S. Jansen, R. Lopez, I. Tomaskova, C.M. Padilla-Diaz, E. Badel, R. Burlett, A. King, N. Lenoir, N.K. Martin-StPaul, and S. Delzon. 2017. Xylem resistance to embolism: Presenting a simple diagnostic test for the open vessel artefact. New Phytol. 215:489-499.

Torres-Ruiz, J.M., S. Jansen, B. Choat, A.J. McElrone, H. Cochard, T.J. Brodribb, E. Badel, R. Burlett, P.S. Bouche, C.R. Brodersen, S. Li, H. Morris, and S. Delzon. 2015. Direct X-ray microtomography observation confirms the induction of embolism upon xylem cutting under tension. Plant Physiol. 167:40-43.

Tyree, M.T., H. Cochard, P. Cruiziat, B. Sinclair, and T. Ameglio. 1993. Drought-induced leaf shedding in walnut: Evidence for vulnerability segmentation. Plant Cell Environ. 16:879-882.

Tyree, M.T. and J.S. Sperry. 1989. Vulnerability of xylem to cavitation and embolism. Annu. Rev. Plant Biol. 40:19-36.

Vahdati, K., N. Lotfi, B. Kholdebarin, D. Hassani, R. Amiri, M.R. Mozaffari, and C. Leslie. 2009. Screening for drought-tolerant genotypes of Persian walnuts (Juglans regia L.) during seed germination. HortScience 44:1815-1819.

Wheeler, J.K., B.A. Huggett, A.N. Tofte, F.E. Rockwell, and N.M. Holbrook. 2013. Cutting xylem under tension or supersaturated with gas can generate PLC and the appearance of rapid recovery from embolism. Plant Cell Environ. 36:1938-1949.

Wortemann, R., S. Herbette, T.S. Barigah, B. Fumanal, R. Alia, A. Ducousso, D. Gomory, P. Roeckel-Drevet, and H. Cochard. 2011. Genotypic variability and phenotypic plasticity of cavitation resistance in Fagus sylvatica L. across Europe. Tree Physiol. 31:1175-1182.

Zimmermann, M.H. 1983. Xylem structure and the ascent of sap. Springer Verlag, Berlin, Germany.

Zimmermann, M.H. and A.A. Jeje. 1981. Vessellength distribution in stems of some amrican woody plants. Can. J. Bot. 59:1882-1892. 